\title{
РЕГИОНАЛЬНАЯ ИДЕНТИФИКАЦИЯ
}

И САМОИДЕНТИФИКАЦИЯ ЖИТЕЛЕЙ ПРИЕНИСЕЙСКОЙ СИБИРИ: ФОЛЬКЛОРНЫЙ, ЭТНОГРАФИЧЕСКИЙ, ЛИНГВОКУЛЬТУРОЛОГИЧЕСКИЙ, ЛИТЕРАТУРНЫЙ ДИСКУРСЫ И ИХ АКТУАЛИЗАЦИЯ ПОСРЕДСТВОМ ИНТЕРАКТИВНОЙ КАРТЫ

\author{
REGIONAL IDENTIFICATION \\ AND SELF-IDENTIFICATION OF THE RESIDENTS \\ OF THE YENISEI SIBERIA: FOLKLORE, ETHNOGRAPHICAL, \\ LINGUOCULTUROLOGICAL AND LITERARY TYPES \\ OF DISCOURSE AS WELL AS THEIR ACTUALIZATION \\ BY MEANS OF THE INTERACTIVE MAP
}

DOI: 10.12731/2077-1770-2017-3-7-22

УДК 82-34

\section{ОТРАЖЕНИЕ РЕГИОНАЛЬНОЙ САМОИДЕНТИФИКАЦИИ В АВТОБИОГРАФИЧЕСКОЙ ПРОЗЕ ПИСАТЕЛЕЙ ПРИЕНИСЕЙСКОЙ СИБИРИ}

Бахор Т.А., Зырянова О.Н., Мазурова Н.А.

Цель. Статья посвящена выявлению показателей процесса региональной самоидентификации, воплощенной в автобиографической прозе, созданной непрофессиональными авторами - жителями Приенисейской Сибири в начале XXI в. Объектом рассмотрения стали произведения, опубликованные в региональных журналах и альманахах.

Методология и методы проведения работы. При анализе автобиографической прозы актуализируются историко-культурный, литературный, этнографический дискурсыл. Используются методы дискурсивного, контекстуального и семантического анализа.

Результаты. Представленные в автобиографической прозе события календарно-хозяйственного ияикла (Пасха, помочи, уборка 
дома, постройка зимовья и др.), народный календарь, семейные праздники, по мнению авторов статьи, отражают неосознанное стремление сибиряков к конструированию этнической идентичности, в основе которой - нравственно-эстетический идеал народной крестьянской культуры, определяюший отношение человека к природе, семейные ценности, хозяйственный порядок.

Область применения результатов. Материаль статьи могут быть использованы при чтении спецкурсов, посвященных проблемам региональной идентификации и самоидентификации, фольклора, этнографии и культуры Приенисейской Сибири.

Ключевые слова: региональная самоидентификация автора; автобиографическая проза; этнокультура; этническая идентичность; дом; народный календарь; дискурс; Приенисейская Сибирь.

\section{THE REFLECTION OF REGIONAL SELF-IDENTIFICATION IN AUTOBIOGRAPHICAL PROSE OF THE YENISEI SIBERIA AUTHORS}

\section{Bakhor T.A., Zyryanova O.N., Mazurova N.A.}

Purpose. The article is devoted to characteristic of the regional self-identification process, reflected in the autobiographical prose of the Yenisei Siberia region authors created in the 20th century. The objects of consideration are works published in regional journals and almanacs.

Methodology. The historical, cultural, literary and ethnographic discourses are actualized in the analysis of autobiographical prose. The techniques of discourse, contextual and semantic analysis are used.

Results. The events of the calendar and economic cycle (Easter, pomochi, house cleaning, construction of winter quarters, etc.) presented in the autobiographical prose, the folk calendar, family holidays reflect the unconscious aspiration of the Siberians to the ethnic identity construction, based on the moral and aesthetic ideal of national peasant culture that defines the relation of man to the nature, family values, economic set-up. 
Practical implications. The materials of the article can be used when reading special courses on the issues of regional identification and self-identification, folklore, ethnography and culture of the Yenisei Siberia.

Keywords: regional self-identification of the author; autobiographical prose; ethnoculture; ethnic identity; house/home; folk calendar; discourse; the Yenisei Siberia.

Признавая тождественность терминов «идентичность», «самосознание» и «самоопределение», считаем необходимым акцентировать внимание на том, что первый из них «фиксирует заостренно-отрефлектированные и символически маркированные моменты авторского самосознания в поисках самотождественности, его «кристаллизацию» [1]. При работе с литературным материалом мы исходили из наблюдения литературоведов о том, что провинциальные писатели конца XX - нач. XXI вв. приближаются «к непосредственному и острому переживанию своей идентичности, вырабатывая территориальное самосознание» [1]. Исходя из этого, основное внимание уделяем тому, как процесс самоидентификации проявляется в автобиографической прозе - «ретроспективном повествовании о себе, первостепенное значение в котором имеют события частной жизни и история становления личности рассказчика» $[18$, с. 10].

Несмотря на активные исследования автобиографической литературы отечественными и зарубежными учеными (С.С. Аверенцев, Л.Я. Гинзбург, Г. Гюсдорф, Г.Г. Елизаветина, Ф. Лежен, С.И. Машинский, Г. Миш, М. Медарич, Н.А. Николина, В.Л. Рабинович, Т.В. Радзиевская и др.), мы все еще можем говорить о том, что на данный момент нет единой общепризнанной классификации и определений автобиографических жанров (исповедь, мемуары, автобиография, дневник и др.).

Вслед за одним из наиболее авторитетных в этой области зарубежных литературоведов $Ф$. Леженом наиболее существенными признаками автобиографической литературы мы также будем считать номинальное совпадение автора, повествователя/рассказчика 
(героя), повествование о частной жизни создателя произведения, ретроспективность изображения, преимущественно хронологическую последовательность изложения, прозаическую форму» и др. $[19$, с. 6-26].

Исследователи неоднократно указывали на то, что «автобиографические произведения, ориентированные на правдивое отражение действительности, не всегда отличаются достоверностью», т.к. «в них имеет место не столько правда факта, сколько правда человека, личности, осмысляющей мир вокруг себя и себя в этом мире» [9]. Исходя из вышеизложенного, основное внимание будем уделять деятельности региональных писателей, которых часто относят к авторам «второго ряда» («самодеятельным», «непрофессиональным» и т.п.), т.к., по общеизвестному замечанию Ю. Тынянова, не только творчество «литературных генералов» определяет особенности историко-литературного процесса эпохи. Безусловно, более выпукло, отчетливо и наглядно закономерности литературного процесса, особенно литературный дискурс региональной самоидентификации, представлены в творчестве региональных писателей, репрезентирующих локально обусловленную художественную картину мира. При этом следует учитывать, что речь идет не столько о художественном воплощении специфических природных и/или социально-культурных обстоятельств, сколько о «специфической интерпретации общего» (в терминологии С.Ю. Неклюдова), под которым, прежде всего, имеется в виду инвариант народной культуры. Среди зарубежных ученых, работающих в этой области, для нас актуальными являются наблюдения С. Хантингтона, неоднократно подчеркивающего превалирование общечеловеческих ценностей в национальной идентичностии [17, с. 75-85] и указывающего на то, что большинство людей считает самой важной культурную идентичность [16]. В этом контексте вполне органично наше обращение к автобиографической прозе, т.к. «тяга к самопознанию - не только актуальное умонастроение, но и родовое свойство русской культуры» [1]. Более того, именно автобиографической прозе, по справедливому замечанию Л.Б. Караевой, принадлежит особая роль «в формировании па- 
раметрической модели самоидентификации», включающей в себя этнокультурную, пространственную и др. составляющие [7, с. 123].

Проблемам региональной идентификации уделяют большое внимание известные фонды (РГНФ, РФФИ и др.), активно поддерживающие изучение ее различных аспектов, в т.ч. и касающихся Приенисейской Сибири. Современные исследователи рассматривают отражение процесса самоидентификации в языковой картине мира жителей региона $[2 ; 8 ; 14 ; 15]$, выявляют маркеры региональной самоидентификации в гимнах малых городов, поселков и в лирических стихотворениях, воспевающих природу родного края $[3 ; 4 ; 6]$.

При отборе произведений автобиографической прозы, созданных авторами - жителями названного региона, мы использовали такие издания, как «Новый Енисейский литератор» (литературный альманах), «Енисей» (литературно-художественный и краеведческий журнал красноярских писателей), «Радуга» (художественно-публицистический альманах Лесосибирского городского литературного клуба») и др.

Этнокультурная составляющая процесса самоидентификации представлена в автобиографических произведениях, повествующих о распространенных в Сибири старинных праздниках, обрядах и ритуалах, ремеслах и т.п. Своеобразное, неосознанное носителями конструирование этнической идентичности представлено в малой прозе М. Кузьминой как следование родовым/семейным традициям. Так, ее рассказ «Пасха» [12, с. 29-33] начинается характерным для автобиографического нарратива указанием на ретроспективность изображения: «Вспоминаю события более чем полувековой давности. Мы готовимся к Пасхе» [12, с. 29-30]. Далее подробно описывается уборка дома, являющаяся этапом подготовки к празднику: «дом уже выбелен < ..> все перемыто и вычищено < ..> Домотканые половики мы стирали в бане щетками, потом папа приводил из колхозной конюшни коня, запряженного в сани, эти половики грузили в них и везли полоскать на речку...» [12, с. 29-30]. Здесь отчетливо проявляется народное православие, синкретично сочетающее религиозные и языческие верования и обряды. Упоминаемые домотканые половики, как известно, относятся к оберегам, 
актуализирующим жизненные силы человека. Таковы домотканые дорожки, расстилаемые вдоль половиц - символ ровного пути, жизненной дороги. Круглые и овальные самодельные коврики являются солярными знаками - оберегами для человека, разделяя свое и чужое пространство. Упоминаемое в рассказе М. Кузьминой полоскание дорожек в проруби заставляет вспомнить т.н. «пасхальные ручьи», символизирующие грядущее обновление мира.

Как видим, в этом рассказе представлен процесс реконструирования миропорядка в пороговый период жизни человека/человечества - перед христианским праздником, знаменующим переход от смерти к жизни. Именно так ощущался и переживался это праздник в период, когда запрещено было отмечать календарные даты, связанные религиозными событиями: «Мы не знали тогда о страданиях Христа, о великом торжестве его Воскресения. Но мы ощущали эту радость, она была в наших душах. Мы готовились к этому празднику, интуитивно чувствуя, что это всенародное торжество» [12, с. 33].

Отражение важнейшей пасхальной символики мы видим в особом отношении сибиряков к цветам, используемым для украшения дома: «...посредине карниза мама прикрепляла для красоты огромный бумажный цветок. Эти цветы сделаны были из разноцветной бумаги и казались нам сказочно красивыми» [12, с. 31]. Как известно, пасхальные цветы символизируют воскрешение природы после зимних холодов.

Политика Советского государства, направленная на искоренение религии как несовместимой с марксистско-ленинской идеологией («...в то время о Боге никто особо не говорил...» [12, с. 32]), требовала новых технологий, нацеленных на создание современных для того периода моделей идентификации. По мнению ученых, «искусство советского плаката как рационально организованная сфера масштабного производства и распространения идеологически заряженных образов» и стало «принципиально новой для российской культуры технологией» [10, с. 9]. В рассказе М. Кузьминой «Пасха» отражено, по мнению историков, характерное для середины XX в. расширение «зоны воздействия» плаката за счет вовлечения «нового пространства 
его функционирования» (деревенской избы, городского интерьера) $[10$, с. 9]: «Чтобы в избах было еще наряднее, женщины покупали у почтальона большие красочные плакаты, славящие партию, передовиков производства, пионеров и комсомольцев: «О, как нам нравились эти “картины”, которые наши родители прибивали гвоздиками на стене! Приходя к друзьям, мы рассматривали у них такие же “картинные галереи“. Плакаты висели до следующей побелки, т.е. 7 ноября, а там заменялись новыми» [12, с. 32]. Как видим, плакаты репрезентировали авторитетные для этого периода модели идентификации в форме «культурных стереотипов» [10, с. 8]. Эти плакаты, прославляющие передовиков производства, пионеров-героев и др., становятся существенной составляющей иконографии «советского человека». Подобные модели идентификации помогали «человеку ориентироваться и планировать собственные стратегии адаптации и интеграции в пространстве советской культуры [10, с. 16].

В народном сознании XX в. Пасха была составной частью природно-хозяйственного цикла праздников, посредством которого осуществлялась трансляция передающихся от поколения к поколению знаний об устройстве мира и месте в нем человека, что, в свою очередь, способствовало этнокультурной идентификации и самоидентификации человека. Такое представление о народном календаре дано в автобиографическом рассказе М. Кузьминой «Листая календарь»: «<..> правильно или неправильно поступали односельчане, перемешивая языческие обряды с православными. Никто об этом даже не задумывался. Жили и жили, как велось исстари» [12, с. 34]. В середине XX в. для сибирской деревни народный календарь был более важен, чем официальный: «<.. > хоть и висели в каждой избе $<\ldots>$ строгие календари социалистической эпохи, жизнь деревни шла по своему, особому календарю-месяцеслову с его удивительными названиями - Петр-полукорм, Еремей-запрягальник, Евдокия-Капельница...» [там же]. Даты этого календаря связаны с трудовой жизнью земледельца: «Петр-полукорм - значит, к этому дню половина корма израсходована, экономно рассчитывай, хозяин, то, что осталось» [там же]. 
Социокультурный синкретизм, характерный для народного календаря, М. Кузьмина объясняет свойственным для жителей Приенисейской Сибири представлением о тесной связи трудовой деятельности и природы: «Чередование сезонных событий, особенно в деревнях, где люди пахали и сеяли, растили скот, во многом зависели от милостей природы, всегда укладывались в этот закрепленный по дням и неделям круг крестьянского труда, круг домашнего, семейного и мирского быта, круг праздников, обычаев и традиций, круг явлений природы» [12, с. 34]. Так в рассказах М. Кузьминой проявляется характерное для автобиографической прозы стремление увидеть в собственном частном личном опыте инвариант народной культуры.

Наиболее зримо проблема идентичности связана с топосом дома, воплощающем целостную картину мира. В автобиографических произведениях образ дома, в котором прошли детство и юность, позволяет рассказчику вернуться к своему изначальному «я», осмыслить свой жизненный путь.

Дом становится центральным образом в рассказах М. Кузьминой «Отчий дом», В. Глуховой «Папа, расскажи мне случай», С. Зеленковой «На два дня в прошлое», А. Янжулы «Помочь» и др. С домом связана обыденная жизнь деревенской семьи, в его пространстве происходило приобщение к традициям, укреплялась связь поколений: «Как часто ты снишься мне, старый деревенский дом <..> Щедрые и открытые жили здесь хозяева, мои мать и отец, вырастившие нас, шестерых детей $<\ldots>$ Семнадцать внуков считали этот дом своим...» [11, с. 42-43].

С образом деревенского дома, являющегося символом целостного и единого бытия, соотносятся в автобиографической прозе главные ценности и смысл человеческого существования, среди которых почитание предков, уважение к человеку и его природному окружению и др.: «В субботу после бани накрывался в самой большой комнате длинный стол, и садилась вся наша семья, человек около тридцати. Наверное, тихо радовался наш дом, видя такое многолюдье. В этих стенах угасали споры и распри, даже будучи недоволь- 
ны друг другом, здесь мы мирились...» [11, с. 42-43]. Как видим, дом, представляя отграниченное от внешнего мира пространство, защищает человека не только от неблагоприятного природно-климатического воздействия, но и «является «уменьшенной моделью мира, позволяющей сохранить образ Космоса и препятствующей возвращению в Хаос» [13, с. 121], с которым и соотносятся враждебные человеку силы и устремления (вражда, зависть, неприязнь).

В автобиографических произведениях сибиряков дом предстает как «место жизнеосуществления человека и как способ его существования в рамках культуры... Дом является реалией, многостронне осваиваемой человеком в различные жизненные периоды и во многом составляющей смысл и цель жизни» [13, с. 121]. Это отчетливо проявляется в воспоминаниях А. Янжулы в картинах помочи - работ, выполняемых с помощью родственников и соседей: «Помочью» - когда собирают родню, друзей и соседей для разовой работы - в Сибири много чего делают. Надо сруб на дом поставить - созывай «помочь», за день поставят. Колодец ли выкопать, капусту на зиму пару бочек посолить, да мало ли чего по-крупному надо сделать. Коли ты хороший человек и в обществе тебя уважают - только свистни да стол накрой, а работников валом навалит. Работу гужом ломанут, а потом ещё и погуляют вволю» [5, с. 198].

Сооружение нового подвала на месте разрушенного и сгнившего у бабушкиного дома характеризуется А. Янжулой как процесс события, «затрагивающего смысложизненные основы человеческого бытия» $[13$, с. 121]. Участие в помочи становится мерой трудолюбия, нравственности человека, т.к. утверждаются смыслообразующие для его жизни ориентиры: «Прошло уже много лет... Я сам сегодня старше мужиков, копавших тот подвал, но я до сих пор отчётливо, порой до мелочей помню, как они работали. Песня, а не работа! Столько в них было радости оттого, что молодые, здоровые, что можно работать так, что черена у лопат гнутся, что это работа на людях, а от этого сил ещё больше прибавляется» [5, с. 201].

Большое внимание уделено в автобиографической прозе зимовью как временному охотничьему дому, в художественном осмыслении 
которого региональные писатели более резко акцентируют его противостояние с внешним миром: «...весёлая и уютная золотисто-янтарная избушка, а в ней для всякого попавшего в беду путника есть и соль, и спички, и топор, и пила, и рыболовная леска с крючками, и рисовой крупы на неделю, и муки на три дня. Мы подумали о тебе, страждущий путник, так, войдя в наше жилище, подумай же и ты о других страждущих - не разори, не укради, заклинаю тебя - будь Человеком!» [5, с. 35].

Созидание является свойством, отличающим человека от животного: «Вся избушка изнутри янтарно светится свежеструганной древесиной и пахнет деревом и смолой. Любовно оглядываю стены, потолок, нары, стол, дверь, смотрю и на свои мозолистые руки, перепачканные древесной смолой, и с удивлением и гордостью думаю: «Ведь это ж всё сделано вот этими моими руками!» [5, с. 35].

Расположение зимовья («своего», обжитого пространства) в тайге (чужом, враждебном мире, опасном для человека) обостряет борьбу духовного и природного, переводя ее из метафизической плоскости в онтологическую. Об ответственности человека перед Космосом говорит А. Буйволов в рассказе «Мое зимовье», вспоминая о завещании отца, горько переживающего смерть потерпевшего аварию над тайгой летчика, не сумевшего воспользоваться зимовьем, ранее разоренным ворами: «Вот, сынок, все, что знал и умел, передал тебе $<\ldots>$ Пусть воруют, сынок, пусть. А ты оставляй, все равно оставляй! Помни, сынок, не для них, воров, оставляешь, а для доброго, страждущего человека. Из горсти добрых семян хоть один росток да взойдет, вот и сей всю жизнь. Нынче земля-матушка шибко в добрых ростках нуждается!.. Все мы люди, все мы человеки, и все плохое и хорошее - все наше, все общее, нами рожденное, нами и вскормленное. Помни об этом, сынок, - вот и все мое завещание» [5, с. 36]. Описанное таким образом в рассказе зимовье становится средством самоидентификации человека в его отношении с окружающей природой, с социумом, с Космосом, о чем свидетельствует избранная автором система координат: «Да, конечно, зимовье наше не Бог весть какое строение, не храм, всего лишь избушка, но в ней 
наш привет и приют Человеку, и мы уходим от нее с легким сердцем и чистой душой» [5, с. 36].

Таким образом, автобиографическая проза, воплощая процесс художественного самопознания, самосознания, саморефлексии жителей Приенисейской Сибири, отражает сложную параметрическую модель региональной самоидентификации как интегрирующего начала, актуализирующего жизнесмысловые ориентации личности. В произведениях определяются мера тождества модели жизни современного человека с тем образцом, которым, по мнению авторов, являлась жизнь предыдущего поколения, стремящегося к гармонии мира и человека. На это нацелены пороговые обряды и ритуалы, способствующие защите «своего» пространства и выстраиванию отношений с «чужим миром». Этому служит и стремление региональных писателей увидеть в насаждаемых культурных стереотипах инварианты народной культуры, объединяющей в гармоническое целое индивидуальное и коллективное, будничный быт и духовное бытие.

Исследование выполнено при финансовой поддержке Российского фонда фундаментальных исследований, Правительства Красноярского края, Красноярского краевого фонда поддержки научной и научно-технической деятельности в рамках научного проекта №16-14-24005.

\section{Список литературы}

1. Абашева М.П. Русская проза в конце XX в.: становление авторской идентичности: Дис. ... Д-ра филол. наук. Екатеринбург, 2001. 409 с. URL: http://www.dissercat.com/content/russkaya-proza-v-kontse-xx-vstanovlenie-avtorskoi-identichnosti\#ixzz4poQK1pCB (дата обращения: 15.08.2017).

2. Бахор Т.А., Зырянова О.Н., Лобарева В.С. Ассоциативные поля как воплощение региональной самоидентификации // Инновационные технологии научного развития: сборник статей международной научно-практической конференции (20 октября 2016 г., г. Казань). В 3 ч. Ч.3. Уфа: АЭТЕРНА, 2016 г. С. 83-84. 
3. Бахор Т.А., Зырянова О.Н., Мазурова Н.А. Региональные гимны как форма актуализации основных маркеров идентичности в локальном тексте // Современные исследования социальных проблем. 2016. № 3-2 (27). С. 105-119.

4. Векессер М.В., Мамаева С.В., Славкина И.А., Шмульская Л.С Проявление региональной самоиндетификации автора в поэтическом дискурсе // Современные исследования социальных проблем. 2016. № 3-2 (27). С. 120-134.

5. Енисей: литературно-художественный и краеведческий журнал красноярских писателей / Редкол.: С. Кузичкин (и.о. гл. ред.) и др. 2008. № 1 (227). 212 с.

6. Зырянова О.Н., Бахор Т.А., Мазурова Н.А. Дендрологические образы как форма проявления региональной идентичности в творчестве поэтов Красноярского края // Современные исследования социальных проблем. 2016. № 3-2 (27). С. 195-207.

7. Караева Л.Б. Опыт этнокультурной самоидентификации в английской автобиографии XX века // Филология и культура. 2013. № 2 (32). С.123-126.

8. Мамаева С.В., Славкина И.А., Шмульская Л.С., Веккессер М.В. Социолингвистический портрет школьников - подростков как речевой маркер региональной идентичности // Успехи современной науки. 2016, №9, том 4. С. 47-49.

9. Маратканова С.С. Автобиографический жанр в пермских литературах начала XX века (Кедра Митрей, К. Жаков). Автореф. дис. ... канд. фил. наук. Саранск, 2005. 27 с. URL: http://www. dissercat.com/content/avtobiograficheskii-zhanr-v-permskikh-literaturakh-nachala-xx-veka-kedra-mitrei-k-zhakov (дата обращения: 07.10.2017).

10.Николаева М.Ф. Советское плакатное искусство как материал для культурологического исследования // Ярославский педагогический вестник. 2012. №1. Т.1 (Гуманитарные науки). С. 323-326.

11. Радуга: художественно-публицистический альманах Лесосибирского городского литературного клуба / Редкол.: Т.П. Попова (гл. ред.) и др. Красноярск: Класс плюс, 2013. № 2. 325 с. 
12. Радуга: художественно-публицистический альманах Лесосибирского городского литературного клуба / Редкол.: Т.П. Попова (гл. ред.) и др. Красноярск: Класс плюс, 2015. - № 3. 330 с.

13. Рымарович С.Н. Дом в философской картине мира // Ученые записки Российского государственного социального университета. 2012. №2. С. 120-124.

14. Славкина И.А., Шмульская Л.С., Мамаева С.В., Веккессер М.В. Вербальные маркеры региональной идентичности (на материале современных чоконимов) // Современные исследования социальных проблем. 2016. № 3-2 (27). С. 227-243.

15.Шмульская Л.С., Славкина И.А., Веккессер М.В., Мамаева С.В. Отражение территориальной идентичности в письменных работах школьников // Успехи современной науки. 2016. №9. Т. 4. С. 67-69.

16. Huntington S. The Clash of Civilizations and the Remaking of World Order. N.Y.: Simon and Schuster, 1996. 367 p.

17. Huntington S. Who are we? The challenges America's National identity. N.Y.: Simon and Shuster, 2004. 448 p.

18. Lejeune Ph. Pour l'autobiographie: chroniques. Paris: Seuil, 1998. 247 p.

19. Lejeune Ph. Signes de vie. Le pacte autobiographique 2. Paris: Seuil, 2004. 273 p.

\section{References}

1. Abasheva M.P. Russkaja proza v konce XX v.: stanovlenie avtorskoj identichnosti [Russian prose in the late XX century: Establishment of the author's identity]: Dis. ... d-ra filol. nauk. Ekaterinburg, 2001. 409 p.

2. Bahor T.A., Zyrjanova O.N., Lobareva V.S. Associativnye polja kak voploshhenie regional'noj samoidentifikacii [Associative fields as an embodiment of regional self-identification]. Innovacionnye tehnologii nauchnogo razvitija: sbornik statej mezhdunarodnoj nauchno-prakticheskoj konferencii [Innovative technologies of scientific development: a collection of articles of the international scientific and practical conference (October 20, 2016, Kazan)]. Ufa, 2016, pp. 83-84.

3. Bahor T.A, Zyrjanova O.N., Mazurova N.A. Regional'nye gimny kak forma aktualizacii osnovnyh markerov identičnosti $\mathrm{v}$ lokal'nom tekste 
[Regional anthems as a form of actualization of main identity marker in local text]. Sovremennye issledovanija social'nyh problem, no 3-2 (27). 2016, pp. 105-119.

4. Vekkesser M.V., Mamaeva S.V., Slavkina I.A., Shmul'skaja L.S Projavlenie regional'noj samoindetifikacii avtora v pojeticheskom diskurse [The manifestation of the author's regional self-identification in poetic discourse]. Sovremennye issledovanija social'nyh problem, no 3-2 (27). 2016, pp. 120-134.

5. Enisej [Yenisey] / S. Kuzichkin et al. 2008. № 1 (227). 212 p.

6. Zyrjanova O.N., Bahor T.A, Mazurova N.A. Dendrologicheskie obrazy kak forma projavlenija regional'noj identichnosti v tvorchestve pojetov Krasnojarskogo kraja [Dendrological images as a form of manifestation of regional identity in the work of poets of Krasnoyarsk Krai]. Sovremennye issledovanija social'nyh problem, no 3-2 (27), 2016, pp. 195-207.

7. Karayeva L.B. Opyt etnokul'turnoy samoidentifikatsii v angliyskoy avtobiografii XX veka [The experience of ethnocultural self-identification in the English autobiography of the twentieth century]. Filologiya i kul'tura, no 2 (32), 2013, pp. 123-126.

8. Mamaeva S.V., Slavkina I.A., Shmul'skaja L.S., Vekkesser M.V. So-ciolingvisticheskij portret shkol'nikov-podrostkov kak rechevoj marker regional'noj identichnosti [Sociolinguistic portrait of teenage schoolchildren as a speech marker of regional identity]. Uspehi sovremennoj nauki, no 9, tom 4, 2016, pp. 47-49.

9. Maratkanova S.S. Avtobiograficheskiy zhanr v permskikh literaturakh nachala XX veka (Kedra Mitrey, K. Zhakov) [Autobiographical genre in Permian literature of the early XX century (Cedar Mitray, K. Jacob)]. Saransk, 2005. 27 p.

10. Nikolayeva M.F. Sovetskoye plakatnoye iskusstvo kak material dlya kul'turologicheskogo issledovaniya [Soviet poster art as a material for cultural studies]. Yaroslavskiy pedagogicheskiy vestnik, no 1, 2012, pp. 323-326.

11. Raduga [Rainbow] / T.P. Popova et al. Krasnoyarsk: Klass plyus, 2013. 325 p. 12. Raduga [Rainbow] / T.P. Popova et al. Krasnoyarsk: Klass plyus, 2015.330 p.

13. Rymarovich S.N. Dom v filosofskoy kartine mira [House/Home in the philosophical worldview]. Uchenyye zapiski Rossiyskogo gosudarstvennogo sotsial'nogo universiteta, no 2, 2013, pp. 120-124. 
14. Slavkina I.A., Shmul'skaja L.S., Mamaeva S.V., Vekkesser M.V. Verbal'nye markery regional'noj identichnosti (na materiale sovremennyh chokonimov) [Verbal markers of regional identity (on the basis of modern choconims)]. Sovremennye issledovanija social'nyh problem, no 3-2 (27), 2016, pp. 227-243.

15. Shmul'skaja L.S., Slavkina I.A., Vekkesser M.V., Mamaeva S.V. Otrazhenie territorial'noj identichnosti v pis'mennyh rabotah shkol'nikov [Reflection of territorial identity in written works of schoolchildren]. Uspehi sovremennoj nauki, no 9, tom 4, 2016, pp. 67-69.

16. Huntington S. The Clash of Civilizations and the Remaking of World Order. N.Y.: Simon and Schuster, 1996. 367 p.

17. Huntington S. Who are we? The challenges America's National identity. N.Y.: Simon and Shuster, 2004. 448 p.

18. Lejeune Ph. Pour l'autobiographie: chroniques. Paris: Seuil, 1998. 247 p. 19. Lejeune Ph. Signes de vie. Le pacte autobiographique 2. Paris: Seuil, 2004. 273 p.

\section{ДАННЫЕ ОБ АВТОРАХ}

Бахор Тамара Андреевна, кандидат филологических наук, доцент, доцент кафедры русского языка, литературы и истории Лесосибирский педагогический институт - филиал Сибирского федерального университета ул. Победы, 42, г. Лесосибирск, Красноярский край, 662543, Российская Федерачия tamarales@mail.ru

Зырянова Ольга Николаевна, кандидат филологических наук, доцент, доцент кафедры русского языка, литературы и истории

Лесосибирский педагогический институт - филиал Сибирского федерального университета

ул. Победьи, 42, г. Лесосибирск, Красноярский край, 662543, Российская Федерация onzyryanova@mail.ru 
Мазурова Надежда Алексеевна, кандидат филологических наук, доцент кафедры русского языка, литературы и истории Лесосибирский педагогический институт - филиал Сибирского федерального университета ул. Победы, 42, г. Лесосибирск, Красноярский край, 662543, Российская Федераџия nadezhda.mazurova.59@mail.ru

\section{DATA ABOUT THE AUTHORS}

Bakhor Tamara Andreevna, Ph.D.in Philology, Associate Professor at the Department of Russian Language, Literature and History

Lesosibirsk Pedagogical University - affiliated branch of Siberian Federal University

42, Pobedy Str., Lesosibirsk, Krasnoyarsky kray, 662544, Russian Federation

tamarales@mail.ru

Zyryanova Ol'ga Nikolaevna, Ph.D.in Philology, Associate Professor at the Department of Russian Language, Literature and History

Lesosibirsk Pedagogical University - affiliated branch of Siberian Federal University

42, Pobedy Str., Lesosibirsk, Krasnoyarsky kray, 662544, Russian Federation

onzyryanova@mail.ru

Mazurova Nadezhda Alekseevna, Ph.D.in Philology, Associate Professor at the Department of Russian Language, Literature and History Lesosibirsk Pedagogical University - affiliated branch of Siberian Federal University

42, Pobedy Str., Lesosibirsk, Krasnoyarsky kray, 662544, Russian Federation

nadezhda.mazurova.59@mail.ru 